Cuadernos de Historia Moderna

ISSN: 0214-4018

https://dx.doi.org/10.5209/chmo.75791

\title{
Comercio redentor: arbitrismo peninsular y proyectismo atlántico en la Monarquía de España (1668-1675) ${ }^{1}$
}

\author{
Pablo Fernández Albaladejo²
}

Recibido: 11 de junio de 2020 / Aceptado: 22 de febrero de 2021

Resumen. Entre los extremos de un arbitrismo irredento y las expectativas de un incierto proyectismo, la Monarquía de España registró -durante el reinado de Carlos II- un sostenido debate sobre los supuestos y la aplicabilidad de la nueva cultura del comercio. Los planteamientos que se formularon, si bien no desconocidos, merecen cuando menos una lectura más detallada. Partiendo del análisis de algunos de esos textos, se revisa aquí el contenido, alcance y limitaciones de ese momento de recepción. Palabras clave. Comercio; arbitrismo; proyectismo; Monarquía de España; Carlos II; Mercantilismo.

\section{[en] Redeeming commerce: Peninsular arbitrism and Atlantic reform projects of the Spanish Monarchy (1668-1675)}

\begin{abstract}
During the reign of Charles II -and ranging from unrepentant arbitrism to the expectations raised by uncertain projects of reform- a sustained debate on the foundations and applicability of the new culture of commerce took place in the Spanish Monarchy. The terms in which the debate was formulated are not completely unknown, but some of the texts which contributed to it deserve a closer reading that reassesses its contents, reach and limits within their original context of reception.
\end{abstract}

Keywords. Commerce; arbitrism; reform projets; Spanish Monarchy; Charles II; Merkantilism.

Cómo citar: Fernández Albaladejo, P. (2021). Comercio redentor: arbitrismo peninsular y proyectismo atlántico en la Monarquía de España (1668-1675), en Cuadernos de Historia Moderna 46.1, 9-29.

\begin{abstract}
Al séptimo [achaque] que es la poca aplicación de la nación española al trato y al comercio, achaque que enflaqueze sumamente el cuerpo de la Monarchía, digo que el daño que de esto resulta, por ninguna parte mejor se conoce que por la oposición de su contrario, pues vemos que la aplicación al trato y al comercio es quien hace ricas y opulentas, las tierras más estériles y más faltas de todo ${ }^{3}$.
\end{abstract}

\footnotetext{
Proyecto MINECO, PGC, 2018-095007-B- 100.

2 Universidad Autónoma de Madrid

E-mail: pablo.albala@uam.es

3 Joseph Arnolfini de Illescas, "Discurso Hispano Politico sobre el estado presente de la Monarquía", marzo de 1662; edición de Cristina Hermosa Espejo con un preciso estudio preliminar: Una mirada a la Monarquía es-
} 
Territorio transitado últimamente por la historiografía modernista, el interés que ofrece el último tercio del siglo XVII aparece ampliamente justificado. Momento de inflexión de la resiliencia hispana, el período se ofrece como un laboratorio en el que se formularon y -en más de un caso- se llevaron a cabo una serie de propuestas encaminadas a asentar esa reorientación. Intermitentemente, una novedosa matriz cultural intentaba habilitarse un espacio en el particular universo de la cultura hispana, no tan impenetrable a admitir en su seno supuestos de fondo que -en última instancia- tampoco dejaban de ser suyos. Los arbitristas de los que se ocupa este trabajo se ubican en ese tiempo de mestizaje y creación cultural, donde hacienda, economía y política se entrecruzaban. Es el contexto en el que se sitúa la cita de José Arnolfini que encabeza este texto. Con el tono preceptivo que caracterizaba sus escritos, Arnolfini advertía en 1662 de los peligros de un comportamiento que, supuestamente constitutivo de la "nación española", se había convertido en uno de los doce achaques que amenazaban con el "descaecimiento" del "Imperio" de la "Monarchia española". Visiblemente contaminado por la sombra de la decadencia propia, el Discurso Hispano Político sobre el estado presente de la Monarquía reiteraba -con alguna diferencia- el argumentario de la tradición arbitrista. Sin dejar de reconocer la gravedad de los doce achaques que enumeraba en su trabajo, no por ello el autor se mostraba convencido de lo inevitable de ese descaecimiento. De hecho, como él mismo reconocía, "no ha llegado nuestro mal a tanto extremo", ni tampoco el propio cuerpo de la monarquia se encontraba tan enfermo como para no permitir medicamentos.

Arnolfini por otra parte no hablaba de oídas. Su trayectoria personal y la propia difusión de sus escritos le avalaban. Su Discurso venía precedido de otro anterior sobre las investiduras del reino de Nápoles (1660), en tanto que un año después concluía su trabajo más conocido, una imaginaria Conferencia y congreso mantenido entre Richelieu, Cromwell y Mazarino. Tanto el argumento como los protagonistas de esa Conferencia ponen de manifiesto la complejidad del registro temático en el que gustaba desenvolverse el político Arnolfini. Sus preferencias aparecían vinculadas a la prolongada actividad diplomática que había venido manteniendo desde tiempo atrás, acreditada en las numerosas comisiones que le fueron encomendadas desde la Corte. Habituado a moverse en esos círculos y bien informado de lo que sucedía en su interior, Arnolfini, atendiendo a la estricta "obligazión" del vasallo para con su "Príncipe", procedía entonces a exponer su particular reflexión sobre el estado de la monarquía. Obviamente lo hacía en clave de política exterior, atendiendo en concreto al complicado escenario abierto a raíz de la paz de los Pirineos y, especialmente, ante la continuidad de la revolución de Portugal. Situado en plena ebullición arbitrista, el escrito de Arnolfini proyectaba sobre todo la mirada del político, de alguien bien informado y receptivo en relación con las novedades doctrinales que se gestaban en su actividad cotidiana.

Ya en un plano doméstico, su letanía de achaques resultaba más bien selectiva. Nuestro hombre insistía en aquellas cuestiones que, vistas desde el exterior, comprometían la credibilidad misma del poder material de la monarquía (pérdida de la vocación militar de la nobleza, falta de poder marítimo). Tampoco desaprovechaba la ocasión para denunciar la presencia de una serie de rasgos negativos que, inducidos en buena medida desde la Corte, imprimían su sello al comportamiento 
colectivo de los vasallos de la monarquía. De entre esos rasgos había que denunciar la presencia de un parroquianismo que dominaba el "genio" de los españoles y que, con frecuencia, les llevaba a "apartarse de las naciones hasta cuando se nos entran por las puertas". La presencia de esa autosuficiencia enfermiza era responsable de la "poca aplicación de la nación española al trato y al comercio", siendo por contra la familiaridad con esa actividad quien estaba detrás de la ascendente posición de Holanda, Zelanda o Génova. Ante esa desafección no cabía recluirse en un narcisismo fatalista y doliente. Era cuestión de afrontar el problema, de impedir que sea "el estrangero" quien "grangea con nuestros frutos, lanas y minerales". De ahí lo apremiante que resultaba sacar las oportunas enseñanzas ante el despliegue técnico y organizativo (tarifas aduaneras, promoción manufacturas, compañías comerciales) puesto en marcha a raíz de las novedosas guerras comerciales destinadas a protagonizar la segunda mitad del siglo. Ordenadamente Arnolfini de Illescas resumía esas novedades, dictando de paso las medidas que urgía adoptar: "Remédiese este mal con la estimazión del trato, fórmense compañías y asociaciones de comercio como las de Holanda y otras partes". Y, complementariamente, "dénse privilegios y manténgase ymbiolables al que fundare en España o adelantare las fábricas de paños y de otras mercancías que con nuestros materiales se fabrican fuera de ella", con la correspondiente reevaluación de las artes mecánicas ${ }^{4}$.

Propiamente no puede decirse que las sugerencias de Arnolfini constituyesen un detallado plan de actuación en relación con el papel a jugar por el comercio pero, tácitamente, se reconocía su dimensión estratégica en la pretendida recuperación de la monarquía. En la medida en que las líneas a seguir carecían de referencias propias, la prosa de Arnolfini tanteaba las ventajas de unas prácticas económicas que, en su momento, serían contempladas por Adam Smith como propias de un superado sistema mercantil. Su perspectiva, en cualquier caso, no atisbaba ninguna convergencia con el lenguaje de una sociedad comercial cuyos cimientos comenzaban a implantarse ${ }^{5}$. Tampoco constituía por lo demás un problema exclusivo de los reinos peninsulares. El protagonismo expansivo que se reconocía a los nuevos modos del comercio no resultaba fácil de implementar sobre unos contextos culturales no necesariamente proclives a esas novedades. Conocemos gracias a los trabajos de John Pocock el tortuoso camino seguido en Inglaterra donde, partiendo de la recepción del humanismo cívico noritaliano y previa reelaboración en el laboratorio político de la isla, llegaría finalmente a alumbrarse el humanismo comercial, un lenguaje capaz de conciliar los supuestos de austeridad virtuosa propios del republicanismo con el universo "crecientemente transaccional del comercio y artes". Esas propuestas empezaban a discutirse asimismo en los cenáculos de la preilustración continental, alimentando a su vez un momento republicano de alcance europeo y, en última instancia, trasatlántico ${ }^{7}$.

Arnolfini, op.cit. (nota 3), pp. 125-26

Hont, I.: "Commercial society and political theory in the eighteenth-century: the problem of Authority in David Hume and Adam Smith", en Welching, W. y Welema W. (eds.): Main Trends in Cultural History, Amsterdam, Rodopi, 1994, pp. 55-94.

$6 \quad$ Pocock, J.: Il momento machiavelliano. Il pensiero politico fiorentino e la tradizione republicana anglosassone (edición original Princeton, 1975), Bolonia, Il Mulino, 1980, esp. vol. II, caps. 13-15; del mismo, "Virtues, rights, and manners. A model for historians of political thought", en Virtue, Commerce and History, Cambridge U.P., 1985, pp. 37-50.

7 Con todo, un sector de la historiografía actual no ha dejado de manifestar sus reservas a la interpretación de 
Hay otros casos que, aparentemente ajenos a esa dinámica del humanismo comercial, empiezan a ser contemplados desde esa perspectiva. Tal por ejemplo el reino de Francia. En el momento en el que ese nuevo relato empezaba a construirse, el reino contaba con su posición de partida, la de una monarquía absoluta en su cabeza al tiempo que corporativamente jerarquizada. A diferencia de los supuestos de origen de ese humanismo, donde el comercio era contemplado como una actividad que formaba parte de la vita activa, en Francia predominaba la concepción del comercio como una actividad que, necesaria para la vida comunitaria, aparecía incapaz de autolegitimarse. Una actividad en última instancia más propia de gobiernos populares que de monarquías. No debe darse por descontado sin embargo que la presencia de ese blindaje corporativo bloquease la asimilación de los supuestos del humanismo cívico. Como vienen sugiriendo los trabajos de Henry C. Clark ${ }^{8}$, Francia no permaneció al margen de esa reflexión, que contó por otra parte con un inatendido protagonista. Sería el ascendente poder real quien finalmente acabaría convirtiéndose en el principal promotor de los valores del comercio, confiriéndoles una relevancia y un lustre equiparables a los de la nobleza. Si en Inglaterra la cuestión central había sido cómo conciliar comercio y virtud, en Francia la cuestión que se planteaba era la de componer honor y virtud. El resultado de ese proceso -ya bajo Luis XIV-será la aparición de lo que el propio Clark ha venido a designar como "comercio dinástico", una nueva versión en última instancia del humanismo comercial.

Aparecido en 1646, Le Commerce honorable del carmelita Jean Eon confirmaba las expectativas que se abrían a partir de esa nueva posición, confiriendo al comercio el cometido de cohesionador del cuerpo social. La posibilidad de llevar adelante esas expectativas fue de la mano con la instauración de una práctica gubernamental que sería definida a comienzos de los sesenta por Colbert. El panorama que se insinuaba en el Comercio honorable contrastaba visiblemente con el Comercio impedido que muy poco antes (1640) había concluido José Pellicer. En el origen de esa reflexión estaba la guerra abierta declarada por Francia en 1635 que había llevado a la adopción de una serie de medidas de "guerra económica". Se discutía sobre si en ese contexto resultaba "útil" a la monarquía mantener "el comercio abierto con Francia y Holanda y sus aliados". Reconociendo la gravedad de la situación, Pellicer avalaba su respuesta recurriendo a la historia, al momento en concreto de los Reyes Católi-

Pocock. Ver Jurdjievic, M.: "Virtue, Commerce and the Enduring Florentine Republican Moment", Journal of the History of Ideas, 62/4 (2001), pp. 721-743. Pincus, S.: "Neither Machiavellian Moment nor Possesive Individualism: Commercial Society and the Defenders of the English Commonwealth", American Historical Review, 103/3 (1998), pp.706-736. Ver también el conjunto de trabajos recogidos en Repúblicas y republicanismo en la Europa moderna (siglos XVI-XVIII), Madrid, FCE, 2017, con introducción de M. Herrero Sánchez. Y específicamente, Hartman, J y Westseijn, A: “An Empire of Trade: Commercial Reason of State in Seventeenth Century Holland”, en Reinert, S. y Roge, E. (eds.): The Political Economy of Empire in the Early Modern World, Londres, Palgrave, 2013, pp. 11-30, A no desatender las últimas consideraciones de Pocock: "The Atlantic Republican Tradition: The republic of the Seven Provinces", Republics of Letters: A Journal for the Study of Knowledge, Politics and the Arts, 2, $\mathrm{n}^{\mathrm{o}} 1$ (2010), pp. 1-10.

8 A quien seguimos en este parágrafo; ver Clark, H.C.: "Commerce, the Virtues, and the Public Sphere in Early Seventeenth-Century France”, French Historical Studies, 21/3 (1998), pp. 415-440 y, más ampliamente, Compass of Society. Commerce and Absolutism in Old-Regime France, Lanham, Lexington Books, 2007, caps. 1 y 2. Interesa asimismo Scornicki, A.: "La France des Lumières et l'humanisme commercial. Bilan et perspectives historiographiques", Histoire,Économie \& Societé, 4 (2013), pp. 76-89.

9 Sobre ese concreto momento, Alloza, A.: "El comercio francés en España y Portugal. La represalia de 1635", en Martínez Shaw, C. y Oliva Melgar, J.M. (eds.): El sistema atlántico español (siglos XVIII-XIX), Madrid, Marcial Pons, 2005, pp. 128-161. 
cos. Ellos habían asentado efectivamente un "buen comercio", sustentado sobre una implacable hostilidad a "las usuras de los hebreos" y sobre la defensa de los "naturales" empeñados en esa actividad. No obstante, la posterior y progresiva "habilitación de extraños" así como la corrosiva extensión de esas prácticas había terminado por eliminar a los "naturales", convirtiendo a los extranjeros en "señores de la mayor parte del comercio". En su opinión, el impedimento en cuestión era consecuencia del prolongado desapoderamiento del que había venido siendo objeto el comercio castellano a manos de los hombres de negocio genoveses y portugueses ${ }^{10}$.

Con su propuesta Pellicer censuraba de hecho la política comercial que venía siguiendo el Conde Duque, interesado desde los primeros momentos en promover la actividad comercial y, según expresión propia, de convertir a los españoles en comerciantes ${ }^{11}$. En el intento de sacar adelante su diseño tampoco había escamoteado naturalizaciones, indultos, ni otras concesiones negociadas con quienes participaban en esa actividad. Ya la sola presencia de esas medidas ponía de manifiesto la imposibilidad de ese retórico retorno a los orígenes apuntado por Pellicer. De hecho, la cuestión no era tanto la imposición de un férreo blindaje confesional sobre el comercio cuanto la de admitir el principio de realidad con el que operaba la monarquía: la consideración del comercio como un recurso instrumental al servicio de la política de grandeur dinástica. La posibilidad de promover el comercio exterior aplicando al propio tiempo un criterio de explotación fiscalista se reveló finalmente como una solución imposible. La evolución de la carrera de Indias durante ese período venía a confirmarlo: el aumento de la presión fiscal produjo el hundimiento de la actividad comercial legal y, alternativamente, llevó a la consolidación de "un sistema internacional de comercio" sustentado sobre el fraude y el contrabando ${ }^{12}$.

Ya en su momento Arnolfini había llamado la atención sobre la delicada situación en la que se encontraba el comercio con Indias, en el que prácticamente no se encontraba "un español tratante que se aproveche de lo que dan aquellos reynos". Cuatro años después el duque de Medina de las Torrres confirmaba ante el Consejo de estado la gravedad de la situación; la indefensión de las Indias era tal que se temía por "el entero menoscabo de su comercio" e, incluso, "la pérdida entera de su dominio"13. Tales perspectivas, por otra parte, no eran ajenas a las ventajosas claúsulas que las Provincias Unidas, Francia e Inglaterra habían conseguido negociar con la

10 Mis referencias a la obra de Pellicer proceden del texto completo de su trabajo que recoge Sánchez Molledo, J.M.: El pensamiento arbitrista en el Reino de Aragón en los siglos XVI y XVII (tesis doctoral, Univ. Complutense, 1997), t. I, vol. II, pp. 1285-86, 1288, 1309,1311, 1320.

11 Fernández Albaladejo, P.: La crisis de la Monarquía, Madrid, Crítica- Marcial Pons, 2009, pp. 95-98

12 Una cumplida y renovada visión de ese proceso se encuentra en los trabajos de José Ma Oliva Melgar ("La metrópoli sin territorio. Crisis del comercio de Indias en el siglo XVII o pérdida del control del monopolio", en Martínez Shaw y Oliva Melgar: op. cit. (nota 9), pp.19-73, p. 57 para mi cita) y de José M. Díaz Blanco, Asi trocaste tu gloria. Guerra y comercio colonial en la España del siglo XVII, Madrid, Marcial Pons, 2012, esp. caps. III y IV.

13 Arnolfini, op.cit. (nota 3), p. 111. “...sólo nos queda [el comercio] de las Indias, y aún en ese son muy pocos los que tratan por sí mismos y en nombre propio... España esta llena de todo género de extranjeros, que todos tratan y todos se enriquecen con nuestros despoxos". La referencia de Medina de las Torres en Antonio Cánovas del C, A.: Estudios del reinado de Felipe IV, en Obras completas, Madrid, Fundación Cánovas del Castillo, 1987, t. I, p.752. Sobre la noción de "pérdida de Indias" en ese contexto -y sobre su principal promotor, el marqués de Varinas- puede verse Fernández Albaladejo, P.: "Intereses de Indias, dominio del rey: indicios de un debate en la Monarquía de España (1680-1715)", en Andrés, F., Martínez, S., y Hernández, M. (eds.): Mirando desde el puente. Estudios en homenaje al profesor James S. Amelang, Madrid, UAM. 2019, pp. 471-482 (damos cuenta más adelante de su actuación) 
Monarquía de España en los tratados de comercio celebrados entre 1650 y 1667. Independientemente de garantizar la protección jurídica y política de sus diásporas mercantiles, la preocupación por el tráfico y por determinados ámbitos del espacio atlántico señalaban la imparable conversión de ese espacio en la cuestión central de los nuevos tiempos, constituido en un "condominio europeo" al margen de las decisiones de la propia Monarquía ${ }^{14}$.

En plena "sima de la Carrera", la conclusión de la guerra contra la Inglaterra de Cromwell puso de manifiesto el estado de postración en el que se encontraba el comercio, obligando a la monarquía a revisar el diseño fiscal con el que venía operando ${ }^{15}$. Coincidiendo con el inicio del reinado de Carlos II -y pese a la inestabilidad política del momento- se percibe una más decidida voluntad en relación con la estratégica cuestión del comercio indiano. Ya en 1665 se alertaba sobre la necesidad de tomar medidas ante la actuación de algunas de esas compañías extranjeras sobre los tráficos propios $^{16}$. Una real cédula de octubre de 1666 aprobaba la creación de una compañía de corso en la corona de Castilla "a semejanza de las compañías orientales y occidentales que tienen formadas los holandeses" y, un año después, un grupo de comerciantes de San Lúcar de Barrameda presentaban a la regente la propuesta de los Capitulos que habrían de concederse para el establecimiento de una nueva compañía de comercio. El contenido del capitulado intentaba seguir de cerca las recomendaciones de la disposición regia. Allí se hacía constar el reconocimiento de dominio sobre aquellas tierras de ambas Indias que "estuviesen por poblar, por descubrir o en poder de piratas y enemigos", actuando como una empresa de colonización y repoblación. Si bien el proyecto no prosperó constituyó no obstante una referencia para nuevas propuestas ${ }^{17}$.

Las inmediatas decisiones de la reina gobernadora confirmaron la continuidad de esa línea de actuación. Así, los componentes de la Junta General de Medios convocada por ella misma en abril de 1668 utilizaron -como material de trabajo de la reuniónun "tratado" significativamente titulado Intereses de la Monarquía de España en la Europa y en la América y del modo de defraudarlos las naciones extranjeras ${ }^{18}$. El objetivo de la reunión era el de descubrir "la forma del comercio que Europa tiene en las Indias de cuenta de los extranjeros", lo que a su vez exigía conocer los retornos que sacan de ellas y "razón de sus valores en Indias, España y en los reinos extraños

14 Para un análisis detallado de esos tratados ver, Pérez Sarrión, G.: La península comercial. Mercado, redes sociales y Estado en España en el siglo XVIII, Madrid, Marcial Pons, 2012, pp. 123-154. Asimismo, Delgado Ribas, J.M.: Dinámicas imperiales (1650-1796). España, América y Europa en el cambio institucional del sistema colonial español, Barcelona, Bellaterra, 2007, pp. 57-69; de este último tomo la expresión "condominio".

15 Díaz Blanco, op. cit. (nota 12), pp. 217-235.

16 Se advertía en concreto de algunas medidas adoptadas recientemente en Inglaterra en relación con el comercio con Canarias: Baltar Rodríguez, J.: "Proyectos de creación de Compañías privilegiadas en Indias durante el siglo XVII", en Barrios, F. (ed.): Derecho y Administración Pública en las Indias Hispánicas, Cuenca, Universidad de Castilla-La Mancha, 2002, vol.1, pp. 249-264.

17 El monarca tenía asimismo la posibilidad de participar en el negocio. Ver la reciente puesta al día de Aragón Ruano, A.: "Las compañías de comercio armado durante el siglo XVII: los proyectos de 1667 y 1668", Obradoiro de Historia Moderna, 25 (2016), pp. 173-205, a quien seguimos en este parágrafo.

18 El "Tratado" se había imprimido en Madrid en ese mismo año, al parecer, no se conservan originales; da noticias de él Dionisio de Alsedo y Herrera en su Descripción de los tiempos de España, 1763, índice de los documentos (que cito por la edición de José María Sánchez Molledo, Madrid, Polifemo, 2005, pp. 381-382). Ver también Matilla, M. J.: "Las compañías privilegiadas en la España del Antiguo Régimen", en Artola, M. (ed.): La economía española al final del Antiguo Régimen, Madrid, Alianza, 1982, pp. 298-99; la opción por el modelo holandés era inequívoca. 
para el conocimiento de su cuidado y del descuido de los españoles". La inclusión de esas orientaciones no era algo improvisado. De por medio la regente había podido conocer un extenso memorial de fray Juan de Castro que, tras remitirlo al Consejo de Hacienda (26 de agosto), llegaría finalmente a la Junta de Medios (29 de agosto). Recibida la consulta del Consejo, la reina encareció asimismo que se "confiriese y comunicase" con el fraile "el muy pormenor fundamento de cada una de sus proposiciones" a efectos de llevar a la práctica aquellas que fuesen "convenientes" y "de mayor facilidad en su execución". El 9 de septiembre Castro exponía las "calidades" de su proyecto así como las "condiciones" para llevarlo adelante" ${ }^{19}$.

Tanto el título como el tono del memorial dejaban constancia de las cuestiones de las que se venía ocupando la reflexión arbitrista, desde la exigencia de una implicación corporativa a los miembros del cuerpo político hasta los objetivos concretos que se perseguían (abolición de las sisas, liquidación del vellón, eliminación de asientos, creación de una banca propia). La metáfora del cuerpo político enfermo que se desangraba se inscribía dentro de esa tradición, lo que daba pie para reclamar la presencia de "hombres peritos", de un saber técnico no muy frecuente en la práctica de la monarquía. Sin recrearse demasiado en esa memoria y sin ocultar su crítica a lo que le parecían enfoques y tratamientos erróneos, Castro apuntaba directamente a lo que consideraba la cuestión central: la constatación de que, desde tiempo atrás, "la falta de comercio dentro del reyno, y de la susbtancia del" venía quedando en manos de extranjeros. Ese desajuste de partida y no los tributos era el origen de "la floxedad de los Españoles" que, finalmente, "dejaron el comercio y el fabricar lo que habían menester". Con sus consecuencias: "el haber dejado a los extranjeros que traigan la ropa que gastamos, y los géneros que les consumimos, es la causa de que lleven nuestros tesoros y dejen exhausto el reino" 20 .

Con abundantes datos cuantitativos de por medio, una elemental aproximación al consumo interior de ropa fabricada fuera del reino arrojaba un balance de 154 millones de pesos de a ocho reales de plata que quedaba en manos de extranjeros. $\mathrm{Al}$ margen de la importación de mercancías europeas con destino al consumo interior, tampoco convenía perder de vista la "destruyción" que causaba a los españoles "el comercio de la Europa a la América" y, a la vez, los "daños" resultantes del comercio de América con Europa. Dado que "no se han hecho ni se han examinado estas materias", Castro se adentraba en un análisis "por mayor y por menor" a fin de que "se reconozca mejor la verdad". El balance era desolador. En el caso del comercio de Europa en las Indias, Castro estimaba que el monto total de los géneros que comerciaban los extranjeros ascendía a 191 millones de pesos, cómputo que él mismo consideraba muy corto ${ }^{21}$. Manteniendo el mismo rigor analítico, nuestro fraile com-

19 "Memorial que dio a la Reyna Governadora Fr. Juan de Castro... sobre que es público y notorio el estado en que se halla la Monarchia y los conocidos riesgos que experimenta, y que por esta razón deven todos los vasallos como partes de este cuerpo político aplicar todo lo que cada uno pudiere para que se conserve, pasando esta obligación a serlo de justicia, por la necesidad en que todos se hallan en su conocimiento", manejo el original de Biblioteca Nacional de España, Madrid [BNE], mss, 10.921, donde existen más copias (mss. 20.261/11 para un resumen que pudo ser el que se remitió a los miembros de la Junta y que recoge las objeciones que se le hicieron al dominico). Una referencia primera en Muñoz Pérez, J.: "El comercio de Indias bajo los Austrias y los tratadistas españoles del siglo XVII", Revista de Indias, 68 (1957), pp. 210-221, esp. 220-221; para otras referencias ver Delgado, op.cit. (nota 14), p. 50.

20 Memorial, fols. 16-17 y 27.

21 Castro operaba con "tres principios": número de personas que había en Indias, tipo de buque que comercia con Indias, y número de mercaderes y de la gente que se embarcaba con ellos. Posteriormente recogía la noticia 
pletaba su investigación calculando "el retorno que los extranjeros sacan en frutos" (exceptuando oro, plata, perlas y esmeraldas). El balance, agrupado por los mismos "principios", estimaba el costo en Indias en 2.979.250 pesos, el valor en España en 8.046.000, y el valor "en los reinos extranjeros" 27.597.625. Tales cómputos hablaban por sí solos, siendo de hecho la causa de nuestra "ruina y destruición"22.

La lectura de los tres primeros "papeles" (de un total de 5 que contenía el memorial) por parte de los miembros de la Junta fue suficiente para que la regente despachase la real cédula de 15 de noviembre 1668 por la que se aceptaban las proposiciones de Castro. Un escrito adicional de esos mismos miembros de la Junta elogiaba incluso la oportunidad del texto de Castro, reconociendo que "no son imaginables inconvenientes que contrapesen a tantas utilidades para embarazar la ejecución de los medios presentes"; el escrito adelantaba incluso que las propuestas contenidas en el cuarto y quinto "papel" merecían ese mismo juicio. Manteniendo su identificación con los planteamientos de Castro, se asumía como propia la crítica al excesivo número de servidores de la flota y ministros de la Casa de Contratación, concluyendo que "la ocupación de arqueadores, guardas, escribanos y demás ministros para este comercio es ceremonia y no verdad". Abundando en esa línea los de la Junta reconocían abiertamente que "todo el comercio Indias, con todo el cuidado del Consejo y de la Contratación de Sevilla" había dado siempre muy poco rendimiento a la Real Hacienda. Un déficit que fácilmente podría solventarse si, además de eliminar esos gastos superfluos "se diere libre el comercio de Indias"23.

Atento y agradecido por esos apoyos, nuestro memorialista insistía antes que nada en la necesidad de "medir la arca de lo cancerado", es decir, cuantificar lo que "los extranjeros sacan de la Monarchia de España y de las Indias". Sus cálculos, que se pretendían cuidadosos y ponderados, no perdían la ocasión de hacer alarde de la tosquedad con la que tradicionalmente operaban los "contadores", habituados a desenvolverse en "teología" y "leyes" e incapaces por tanto de "hacer un juicio de quentas, ni saber suma, ni percibir la monta". La divergencia que se hacía patente ratificaba la gravedad de ese intercambio desigual: los más de 200 millones que se pagaban a los extranjeros "por su trabajo personal y por su industria", representaban una evasión de riqueza a todas luces evitable y que no cabía justificar por la "floxedad" propia. De hecho el ajuste de esa cuenta ponía de manifiesto una pérdida de más de 34 millones para la Real Hacienda, en virtud de lo que le correspondía por sus derechos del 17 1/2 por ciento. Era por tanto el momento de ponderar hasta qué punto la "quenta" por él presentada podía considerarse "verdadera" o "fantástica" 24.

El "alivio" del reino, la posibilidad de "quitar" los tributos, "consumir" el vellón y demás "buenos efectos" que se prometían pasaban en cualquier caso por una exigencia innegociable: que "cada ciudad, cabeza de Reyno tenga consulado como el

pormenorizada de los géneros que los extranjeros comerciaban en los galeones españoles, especificándose toneladas, costo en las naciones, valor en España y valor en Indias. En España las partidas de esos géneros sumaban 31. 637.498 pesos, en tanto que en Indias ascendían a 92. 515.000 (excluyendo aún y todo algunos géneros (Memorial, fols. 16-17, 28-33, 38-51; se omite la detallada exposición cuantitativa y sus propias reservas sobre el manejo de esos datos)

22 Memorial, fols. 45-51, 63-64, 48 para las referencias del texto.

23 Memorial, fols. 65-71, 75-77. La alusión al comercio como ceremonia (fol. 70) se repite a lo largo del texto: "el ser visitadas las naos es un ceremonia y no verdad" (fol. 81).

24 Ibidem, fols. 92-93, 96-101. Para una comparación de la importancia de esas cantidades ver Oliva Melgar op. cit. (nota 12), pp. 19-73. 
de Sevilla, sin dependencia de uno con otro y que cada uno comercie sus frutos". Un "comercio libre" y unos consulados que se extenderían asimismo a los puertos de Indias, en un proceso que finalmente les liberaría de la dependencia de los extranjeros. Adelantándose a eventuales objeciones y "para la mayor calificación de los medios propuestos", el propio Castro se planteaba y "satisfacía" las dudas que pudieran derivarse de su exposición. Respondidas estas últimas, esperaba incluso que "los comercios de Sevilla y Cádiz" no plantearían en este caso ninguna "contradicción" para la ejecución de las "dichas naos sueltas", ya que de lo contrario sería público que "dentro de casa tenemos el mayor enemigo". Castro reiteraba que todo ello probaría "la verdad de mis cómputos imaginarios, o realidades del comercio"25.

Demostrado que el mejor medio para conservar la monarquía era que "la substancia del comercio sea dentro del Reyno", nuestro memorialista -fiel al compromiso contraído con la regente- pasaba a referir aquél otro medio necesario para "aliviar a los vasallos". En este sentido la propuesta de "quitar a los tributos" imponía previamente una actitud proactiva por parte de los propios vasallos, exigía que éstos "dejen la flojedad y que trabajen para sustentarse ellos mismos" que, en última instancia, "se hagan ricos con su trabajo". La opción no era nada irreal. Para la Real Hacienda la eliminación de los tributos quedaba más que compensada con los ingresos obtenidos en el nuevo diseño comercial, un ahorro de cantidades que alternativamente se utilizaría para constituir "un capital que no es del rey ni del reino, sino del común y bien público". Podrían materializarse así unos "Herarios públicos" con los que "se han de socorrer laborantes y materiales, pagar jornales y comprar lo que se beneficiare". El papel de esa institución los asimila a "unos nuevos mercaderes, o asentistas, que nos labren dentro del reino todas las ropas", haciéndose al propio tiempo con su oro y con su plata. Era en definitiva la forma para que los vasallos "gocen de la sustancia que el reino tiene"26.

Tan prometedora expectativa no llovería del cielo. La posibilidad de "hacerse ricos con su trabajo" daba por supuesto la puesta en marcha de un plan de industrialización, la implantación de una especie de colbertismo manufacturero encaminado a conseguir que las "ropas nuestras" sean fabricadas de "nuestras pastas". La utilización del término "comercio pasivo" confirma la presencia de ese lenguaje $\mathrm{e}^{27}$. No otra cosa era lo que enseñaban "las experiencias en todas las naciones". Partiendo de las pilas de bautismo y previniendo de la diversidad de coeficientes a emplear, podía calcularse una vecindad que llegaba a 4.713.900 vecinos (lo que arrojaba un cálculo de 23.569 .500 personas). Previo despacho de reales cédulas a las cabezas de partido y desde allí a los lugares de jurisdicción respectivos, los vecinos de cada pila se obligaban a tener corrientes 3.000 telares para fábrica de lanas y 1.000 para toda fábrica de $\operatorname{sedas}^{28}$. La idoneidad del

25 Ibidem, fols. 94, 101-106, 108-115; la última cita de Castro en fol. 114. Sobre la oposición del Consulado, García Fuentes, L.: "La oposición del Consulado de Cargadores a Indias a la creación de compañías comerciales privilegiadas", Temas Americanistas, (17) 2004, pp. 24-37; ver asimismo más adelante.

26 Castro, Memorial, fols 133-135. Sobre los erarios, Ruiz Martín, F.: "La banca en España hasta 1782", en El Banco de España, una historia económica, Madrid, Banco de España, 1970, pp. 1-196; Dubet, A.: Hacienda, arbitrismo y negociación política, Valladolid, Universidad de Valladolid, 2003.

27 En el resumen del memorial enviado a la Junta se advierte que "una de las principales causas de la pobreza de España es la falta de comercio activo, esto es, que pudiéndose labrar en sus Reynos todas las pastas o materiales crudos que producen... lo dejan contra toda política llevar a los extranjeros" (BN, mss. 20.261/11, fol.1).

28 Memorial, fols. 134-36; detalles concretos en fols. 146-150 y, especialmente 155-175 para una cuantificación detallada por lugares, materias, costes, rendimientos, efectos en la recaudación y estímulos a otros sectores. 
medio propuesto hacía que pudiera ser participado por Valencia, Aragón y Cataluña, "pues son vasallos y españoles; y si se les incluyere en el comercio de Indias, crecerán las rentas reales, uníranse las fuerzas del reino, alimentárase la Armada y naos del comercio y la gente de guerra y se imposibilitará el disfrute que nos hacen los extranjeros todos los años". Podría hacerse lo propio con "Flandes, Nápoles, Milán y demás reinos sujetos a la Corona" $\mathrm{y}$, aún, un hecho más relevante: "poblaránse las Indias y serán de España sin peligro; y es punto, solo esto, que se debe apuntar; que si llegare el caso daré el papel aparte, porque solo navegará el Océano quien tuviere licencia de España". En el improbable caso de que "las Provincias que oy no contribuyen y por esta razón no quisieron poner telares ni entrar en este comercio, príveseles de poder ir ni entrar en las Indias" 29.

Frente al comercio "ceremonia" practicado por la Casa de Contratación Castro contraponía "las realidades del comercio", un plan de modernización de la gestión que dirigiendo el foco hacia el espacio atlántico no por eso se desentendía de aquellas cuestiones que habían venido conformando la tradición arbitrista. Convencido de estar en posesión del "medio" ideal no le cabían muchas dudas de que su propuesta acabaría por imponerse; finalmente "se convencerán todos y confesarán que el comercio es el único fundamento de la conservación y ahumentos de las Monarchias"30. Si bien el proyecto no llegaría a prosperar como tal, algo de esa influencia empezaba a notarse. El 23 de enero de 1669 se disponía el establecimiento de una Compañia española para el comercio armado, a lo que poco después seguían unas "Advertencias" en las que la reina manifestaba su preferencia por el modelo de $1667^{31}$ Tampoco faltó aquí una oposición corporativa planteada por el vicecanciller de la Corona de Aragón Cristóbal Crespí, en desacuerdo con una forma ejecutiva de actuación que iba en contra de la dinámica consiliar constitutiva de la Monarquía.

Previamente, en abril de 1668, la reina había nombrado al marqués de Aytona como "protector" de la futura Compañía, disponiendo la reunión de una "Junta de personas de caudal" para precisar su establecimiento. De acuerdo con los criterios recibidos, se llevaron a cabo conversaciones con comerciantes de Bilbao, Cádiz, Cataluña, Madrid, San Sebastián, Sevilla y Valencia que estuvieron lejos de promover una adhesión masiva al proyecto. En las misivas Aytona hacía notar que, independientemente de fomentar el comercio con las Indias, se trataba asimismo de promover las manufacturas peninsulares. Por su parte el conde de Cervellón, encargado de enviar la carta a los gobernadores del Reino de Valencia, informaba que la intención de la reina era la de que "participemos todos los españoles con igualdad esta combeniencia", pero el entusiasmo tampoco fue aquí la nota dominante. Su definición como "un Asociamiento General en que concurran todos los reynos y Provincias de España" no era ajena del todo a esa petición de incorporación de los sujetos corporativo-territoriales propuesta por Castro, ni tampoco a la voluntad manifiesta de hacerse con el control del comercio propio vinculado al desarrollo de las manufacturas del país. Se trataba en última instancia de que la península dejase de servir "sólo de puente, por donde se transfiere [la riqueza] a las demás naciones" 32 .

\footnotetext{
Ibidem, fols. 151, 154-55, cursiva nuestra.

Ibidem, fol. 152.

31 Matilla: op. cit. (nota 18), p. 298 para la referencia del 23 enero; sobre las características de la nueva compañía ver también Aragón: op. cit. (nota 17), pp. 189-191.

32 Matilla: op. cit. (nota 18), pp. 297-299; Baltar: op. cit (nota 16), pp. 257-58; para mayores detalles de ese proceso, Aragón: op. cit. (nota 17), pp. 195-202.
} 
Tales planteamientos alimentaban la reflexión económica que recorría a la monarquía en el último tercio de siglo, dentro de la que hay que incluir la Reformación moral, política y christiana del comercio propuesta por Juan Cano en 1675. Incorporando en portada una estratégica referencia a su lugar de nacimiento, Cano intentaba hacer notar su condición de "vasallo del primero real patrimonio, y primeros feudos de la primera Stirpe del universo, la Antiquissima y Augustissima Casa de Austria", de súbdito en fin de una monarquía que se pretendía universal ${ }^{33}$. A ese cuerpo político y a la majestad católica de "nuestro Monarca Don Carlos II, Rey de las Españas" dedicaba el autor su trabajo, esperando que la necesidad de desenvolverse en "estrangera lengua" y su propia "falta de estudio" disculpase "sus defectos, impropiedad de lengua, oración y discurso". Era justamente esa carencia la que había estimulado el deseo de servir a su "Rey y Señor natural" y, finalmente, le había llevado a redactar unos "Estatutos, o Arbitrios" para reformar el comercio. El "ofrecimiento" del trabajo incluía al entramado de sujetos corporativos de la monarquía (Grandes, Consejos, Ministros, Títulos y Señores de vasallos), beneficiarios asimismo de su propuesta. Los "comerciantes de la Monarchia de España" y los "Mercaderes Estrangeros" tampoco quedaban al margen: los primeros por la condición de "Depositarios y Mayordomos de la Monarchia" a los que, como premio del cielo y perdón del monarca, los Estatutos les devolvían esa condición; los segundos por la concesión de una serie de privilegios (puerto franco, admisión al comercio de Indias) que les permitirán beneficiarse de "derechos en favor del comercio que siguen los principales centros de Italia, tendrán también la política de las fábricas de Francia, la Gran Compañía de Holanda y la disposición de Inglaterra para evitar los fraudes en el comercio"34.

Condicionado por el alcance de esa promesa y la entidad de los beneficiarios, nuestro hombre no vacilaba en presentarse como un enviado "de parte del Cielo", responsable de comunicar a la monarquía "una nueva para tus Estados favorable". A saber: que el Cielo, como obsequio al monarca por su coronación, "ha aplacado su justa indignación contra tu comercio", y promete en consecuencia la "restauración" de las pasadas pérdidas, la "conservación" de la actual felicidad y la "aumentación" de la futura prosperidad, mediando en justa correspondencia "las gracias que se le deven". Se entendía que ese perdón al comercio por amor del "Divino Dador" iba de la mano con la exigencia de que aquél restituya todo lo que tiene "usurpado" a la monarquía, lo que dejaba la puerta abierta a "mudar todos los albedríos de los comerciantes, y disposición de los medios con los que se sirven con tantos beneficios". Reiterando que su objetivo no era otro que el de "encaminar el comercio en su

33 Reformación moral, política y christiana del comercio, en doze estatutos, que restauran treinta millones de reales de a ocho de renta cada año a la Monarquía Española, Colegida en diez y seis años de experiencias continuas por todas las plaças comerciales del Universo, y puesta a las plantas del mayor Monarca de sus quatro partes. Por Juan Cano, natural de la villa de San Claudio en el Condado de Borgoña, Madrid, 1675 Una primera aproximación a ese trabajo la efectuó Manuel Herrero Sánchez: "Cádiz y la reorganización del comercio indiano en el proyecto mercantilista de Juan Cano (1675)", Actas del II Congreso de Historia de Andalucía, Córdoba, 1994, vol.6, pp. 171-178. Aporta nueva información y perspectivas José M. Díaz Blanco: "Pensamiento arbitrista y estructuras institucionales en la carrera de Indias (siglo XVII): entre la desincentivación y la represión", Anuario de Estudios Americanos, 71/1 (2014), pp. 47-77, esp. 61-68 (como informa este autor -p. 61- Cano presentó una larga serie de memoriales y opúsculos sobre su proyecto entre octubre de 1674 y abril de 1675; la Reformación apareció en enero de 1675)

34 Cano, Reformación, dedicatorias iniciales "A la Magestad Catolica”, "A la Reyna Nuestra Señora”, "Ofrecimiento a lo Grandes", "A la única Monarquía del mundo que manda en sus quatro partes", "A los comerciantes de España” (sin paginación continua). 
debido ser", Cano incluía a continuación un específico "Advertimiento al comercio" donde se hacía constar la responsabilidad moral y el papel redentor que tocaba al comercio en esa refundación.

Para empezar convenía recordar que el comercio no era sino un efecto del pecado, una suerte de pecado original convertido de hecho en el "pecado actual" que había corrompido la Monarquía de España, "del mismo modo que el pecado de Adán todo el linage humano". Su efecto había sido demoledor para monarca, vasallos y reinos, los tres "cuerpos" que componían la Monarquía", a los que había imposibilitado para hacer el bien al tiempo que los mantenía en pecado. De hecho el comercio había vaciado "de todo bien y llenado de todo mal" esos cuerpos. Había terminado por despojar de reputación, honra y fama a los ministros del monarca, obstaculizado el valor de sus armas y favoreciendo, en fin, los triunfos de sus enemigos. Y, lo que era peor, entreteniéndoles con el "vano interés" les había mantenido en pecado "sin que hasta el momento se haya reconocido "confesión válida al paso que importaba la salvación de toda España en ella". La inobservancia de esa dimensión salvífica hacía que el pecado del comercio fuese "treinta mil veces mayor que el de Judas"; después de todo los treinta dineros del apóstol no podían compararse con los treinta millones de los que el comercio - en cada flota- despojaba "al pueblo Católico de Dios y a su Monarcha para darlos al diablo". Responsable de "todos los pecados que se cometen en el mundo", el comercio devenía "compañero de Lucifer". Con el propósito de redimir esa situación y actuando como "fiador", Cano anunciaba la disposición celestial para dejar "su ciudad de Babilonia por la antigua Cádiz", una transformación que implicaba justificaciones de un orden ya más material ${ }^{35}$.

Una señal visible de ese favor la constituía la decisión de la gobernadora de remitir al Consejo de Indias el memorial de los Estatutos lo que, para Cano, venía a confirmar la sensación de haberse cumplido "el tiempo preordinado para introducir bienes y extirpar males" de su "amantísima Monarquía". Se consideraba autorizado por lo mismo para erigirse en interlocutor de un "Diálogo entre la Monarquía de España y el Autor", en cuya confección habían participado activamente las tres potencias del alma ("Inclinación", "Teórica" y "Práctica"). El Diálogo intentaba exponer didácticamente las razones que habían llevado al comercio propio a su situación actual y, como respuesta a ese problema, la inclinación había llevado al autor a realizar un extraordinario periplo de dieciseis años por Filipinas, China, Indias Orientales, Asia, Africa y Europa. Con ello se trataba de conocer de primera mano "los perjuicios advertidos del conocimiento" cuyas conclusiones, una vez recogida la información, no resultaban especialmente alentadoras: todos los perjuicios que padecía la monarquía apuntaban directamente al comercio, a un comercio "mal administrado" del que procedía la plata y, en última instancia, la prosperidad misma de los reinos. En ambos casos las pruebas eran irrefutables. Los males de la Monarquía procedían del comercio, de igual forma que la riqueza de los extranjeros procedía de las Indias. Se trataba en cualquier caso de una situación que podía modificarse. Siendo la de los extranjeros una riqueza "sacada por política y gobierno de sus comercios, aun contra la naturaleza", el propio comercio tenia entonces la solución en sus manos; sólo él sabía "hazer más" que aquella, sólo él "perfecciona con su política lo que aun no supo dibujar con su saber propio". Bien entendido que la "mudanza del comercio" que se proponía exigía que, previamente, los comerciantes debían de apartarse "has-

Cano, Reformación, "Advertimiento". 
ta de su mismo alvedrío y libertad con que comercian hoy", actuando "sin govierno ni orden", haciéndoles entender en definitiva que "esta misma libertad particular ha de ser sugeta a los superiores" 36 .

Más allá de la preceptiva dimensión moral, política y gobierno reivindicaban así su papel, su peso específico en el proceso redentor. Se trababa de ponderar -y eventualmente proceder a- la aplicación de ese saber propio, cuyos resultados a la vista estaban: Venecia y en general toda Italia eran "un non plus ultra de riquezas por su comercio", y la misma conclusión se desprendía de los casos de Francia, Holanda, Suecia, Hamburgo, Inglaterra “y demás reinos del Norte". Ya en las páginas primeras se había referido a las prácticas concretas (tasas fiscales, manufacturas, compañías comerciales) que en cada caso habían impulsado esa dinámica, responsable de una espectacular transformación material de esos reinos y de sus haciendas. Se sabía que el camino a seguir para alcanzar esa situación era relativamente simple: comerciar con géneros y frutos propios con el objeto de introducir plata a cambio, porque "donde un Reyno no tiene ocasión de echar la plata fuera, no puede faltarle prosperidad". La propia España planteaba entonces al Autor la pregunta fundamental: "¿Quién impide que en España no se comercie de esa forma?". La respuesta tenía que ver con la forma misma en que esta "introducido" el comercio, "la mala disposición" de los vasallos y "la poca práctica y ningún gobierno que dan a su comercio". Lejos de actuar como un cuidadoso "mayordomo de la plata", los comerciantes, en vez de conservarla, "la echan toda en pagamento de los géneros que pudieran fabricar, como hacían antes de tener las Indias; de esta forma sus riquezas "en vez de aumentarles la prosperidad son causa de su declinación".

La posibilidad de invertir esa situación pasaba por conseguir que los comerciantes propios "guarden las leyes de la razón de su comercio". Cano veía las cosas con un cierto optimismo, convencido como estaba de la capacidad de unas medidas que, "con la propiedad, aplicación y tiempo oportuno", probarían la eficacia de los medios "naturales" y "ordinarios" por él propuestos. Existían además razones de estricta justicia, de una justa posesión de las Indias que legitimaba la recuperación de las rentas que se perdían por "los efectos injustos de ese comercio". Preguntado por España acerca de los fundamentos y garantías que podía ofrecer su propuesta, el Autor, aun reconociendo su "indignidad y ser idiota sin letras", aducía su prolongado sacrificio personal en la tarea y, en un plano superior, repetía su convicción de que tanto la "Teórica del remedio" como la "Práctica de su eficacia" y la "evidencia de su consecución" eran "disposición del cielo". De ahí la solvencia y aún la trascendencia que cabía conferir a su propuesta: hasta el momento "ningún político, por científico que sea, no ha tratado generalmente de la prosperidad de una monarquía universal por medio de un comercio universal".

A ese objetivo se dirigían derechamente los doce estatutos que culminaban el trabajo, dentro de una lógica presidida por el protagonismo del comercio. De hecho la historia de este último contenía las claves de la situación actual. Después de todo el comercio no era sino "una profesión natural que la naturaleza da sin enseñar en general", consecuencia de "la necesidad de las cosas que cada estado carece". Una actividad que por otra parte se había venido ejercitando con absoluta facilidad y "poco dinero", pero cuyas reglas de juego habían cambiado sustancialmente a raíz de la conquista de las Indias por los españoles. Deslumbrados por sus riquezas, estos

\footnotetext{
Cano, Reformación, "Diálogo", pp. 3-12 para las citas de éste parágrafo y los dos siguientes.
} 
últimos habían abandonado "sus antiguas virtudes y fábricas" quedando en manos de los extranjeros, con el agravante de que lejos de pagar esas compras con sus géneros las pagaban con plata. A la vista estaba que el daño causado por esa"desencaminada" gestión del comercio era inmenso. A ella se debía en última instancia que se hubiera introducido y asentado la ociosidad, "perjuicio capital" del que derivaban dos importantes consecuencias: la declinación de vasallos y la extracción de plata; frente a esta última, la recuperación de los vasallos resultaba secundaria ${ }^{37}$.

A lo largo del trabajo Cano reiteraba la importancia estratégica de su propuesta e indicaba los pasos a seguir. Dado que "el principal poder del Príncipe consiste en el comercio, de cuya administración procede su grandeza, el beneficio de los vasallos y prosperidad de los Reynos", a él correspondía "conseguir la restauración del comercio de malo a bueno", punto del que en última instancia "depende la machina". Sentado ese supuesto de partida, el autor procedía a exponer su aportación personal a esa tarea. Enumeraba así "once perjuicios capitales" directamente derivados de "la deformidad del comercio", a los que oponía "once remedios" capaces de la "restauración de su forma". Adquiridos todos ellos a fuerza de "especulación del entendimiento, comprensión de la memoria y elección de voluntad", esos arbitrios, los Estatutos, condensaban "inmensidad de beneficios" para los referidos tres "cuerpos", conformando una propuesta prudente avalada por la propia "experiencia" y "práctica" del autor ${ }^{38}$.

Un inevitable mestizaje doctrinal informaba el conjunto de las medidas propuestas. Así, la posibilidad de poner fin a la constante declinación de los vasallos implicaba no perder de vista "la política del Reyno de Francia", es decir, atender a las reformaciones generales de Richelieu, Mazarino y Colbert, conocidos por "práctica" y capacitados por "experiencia". De otra parte la estracción de plata y conservación en el reino obligaba a dirigir la mirada a Sicilia, cuya fertilidad natural le permitía organizar un comercio "para vender y sacar plata". Precisamente la propia Italia, vista en su conjunto, representaba el mejor ejemplo sobre el Modo y forma en que se debe comerciar para conseguir lo declarado en los dos primeros Estatutos, (beneficio universal y restauración del mismo comercio a su debido ser), tercer estatuto. Nadie en efecto había sabido aprovecharse tanto del comercio como sus "Príncipes", cuyos preceptos, pragmáticas y estatutos no perseguían otro fin. Bastaba con "administrarlo en gobierno y precepto" para que los males del comercio desparecieran y disfrutar de "todos los beneficios". De acuerdo con las exigencias de ese reglamentismo, los estatutos cuarto y quinto disponían la creación de una Gran Compañia General cuyas referencias de origen tampoco se ocultaban; no eran otras que las de la Gran Compañía general de Holanda. La Compañía dispondría de un Tribunal de Cuentas a quien correspondería "el gobierno del Comercio", tanto a efectos de asegurar la necesaria "aumentación" del mismo cuanto para gobernar la red de administradores dependientes.

Si el objetivo de la Gran Compañía no era otro que el de "quedar la plata en España", la Disposición de Puerto Franco -quinto estatuto- buscaba sobre todo combatir el fraude, instaurando un modo de comercio dirigido a conseguir "beneficio común tanto al Rey por los derechos como a la Monarquía y vasallos". El puerto constituiría un eslabón de la cadena al servicio del comercio, "encadenando todos los demás

Cano, Reformación, "Introducción a los Estatutos"; Estatuto 3 y Estatuto 4.

Cano, Reformación, "Introducción a los Estatutos"; Estatuto 12. 
medios por su medio". Vendría arropado por un completo dispositivo de privilegios que, de hecho, suponían una modificación sustancial de la organización del comercio atlántico hispano. Servían de referencia en esta caso los privilegios otorgados al puerto de Livorno por Fernando I de Médici (1590) y alguna influencia se reconocía asimismo a la reciente conversión de Marsella en puerto franco (1669). Todo ello sin olvidar la "grandeza" que proporcionaría esa construcción a la ciudad donde se asentase esa fábrica, sobre cuya identidad ya venía proporcionando suficientes pistas. La instauración del puerto estimularía las posibilidades del tráfico interior, sirviendo por otra parte como pagamento de "los géneros de Estrangeros", evitando con ello la "estración" de plata, estimulando el cuidado de la cosecha propia y, en última instancia, propiciando una dinámica creciente del propio comercio. De ahí también el sentido de los dos siguientes estatutos, contemplados siempre desde esa lógica de supeditación a los objetivos del puerto franco. Así el estatuto sexto se ocupaba del "modo de aumentar, vender y disponer los frutos de España, en beneficio particular de los dueños, y general por medio del comercio", en tanto que el séptimo atendía al establecimiento de "fábricas de paños de lana para el gasto de la Monarquía y venta de los restantes en Puerto franco para evitar la estracción de plata”.

Dentro de la lógica inclusiva de la Gran Compañía la incorporación de "los comercios de Indias" era pieza fundamental. Toda esa actividad debía de reducirse a dos "cuerpos": el de Perú - con su feria de Portobelo- y el de Nueva España -con la de México- que de esa forma vendrían a disfrutar "de todos los beneficios, como eslabones que dependen de la cadena de España” (estatuto VIII) Ello implicaba una "reformación" de las prácticas existentes previamente informada y argumentada ante la propia Corte, buscando una interacción entre mercaderes y navegantes con Consejos reales y ministros de gobierno. La compañía monopolizaría el comercio colonial, siendo la encargada de conceder permisos de comercio, fijar precios de todos los productos y, muy especialmente, controlar el mercado de la plata. Las transacciones de ámbito menor se llevarían a cabo por compañías provinciales instaladas en los centros más activos. La aplicación de ese plan minimizaría las pérdidas que resultaban del vigente sistema de galeones tanto para "los buenos mercaderes" como, sobre todo, para la hacienda de la propia Monarquía. Se invertiría así la dinámica de un sistema mediatizado por la presencia de encomenderos, comisionistas e intermediarios varios. Lejos de conducirse mayormente hacia los "Reynos Extrangeros", las ganancias, revertirían a los mercaderes nacionales y, muy especialmente, a la hacienda de la propia Monarquía. Se bosquejaba así un novedoso espacio comercial atlántico, que contemplaba extender la nueva situación a otros territorios de la Monarquía, peninsulares y extrapeninsulares ${ }^{39}$.

Del comercio impedido al reformado, pasando por el comercio de ceremonia, el tiempo transcurrido entre el escrito de Pellicer y los de Castro y Cano evidenciaba los límites de una representación que, si no una nueva escritura, planteaba cuando menos la necesidad de reordenar los papeles. Aun compartiendo diagnóstico y el sesgo de las medidas a utilizar, el análisis concreto de una y otra propuesta dejaba entrever sus diferencias. En mayor o menor medida los escritos de Castro hacían suya la memoria de los males que venían siendo puestos de manifiesto por el arbitrismo tradicional (eliminación de arbitrios, consumo de vellón, establecimiento de erarios

Herrero, op. cit. (nota 33), pp. 175-77 
públicos). Si bien su mirada se concentraba en el ámbito peninsular contemplado desde una perspectiva castellana, su planteamiento dejaba entrever la presencia de una lógica unitaria en términos de articulación de un espacio económico interior, insinuando esa península económica que cristalizaría posteriormente ${ }^{40}$. Cano contemplaba las cosas desde otro observatorio, podría decirse que subía la apuesta: proponía habilitar un comercio universal acorde con la dimensión y la propia condición de la monarquía: como la monarquía, el comercio debía de ser universal. Más que la restauración de un reino concreto, la tarea a seguir contemplaba la espacialidad de un conjunto imperial que se ofrecía como habitat privilegiado de los "comerciantes de la Monarchia" y de los "mercaderes extranjeros". Era la situación de esos cuerpos -y no tanto la de los súbditos del monarca- la que inspiraba el sentido de las medidas a adoptar. En última instancia la renovación prometida se encaminaba más a fortalecer los recursos del monarca -y la grandeza de la monarquía- que a la recuperación de los vasallos, sin que en ningún caso dejara de contemplarse este objetivo.

Cuestión crucial en una y otra propuesta, la forma de llevar a cabo el comercio con Indias recogía asimismo esas diferencias entre uno y otro arbitrista. Castro postulaba un "comercio libre" que implicaba la sustitución del monopolio sevillano por un régimen abierto, en convergencia con la tradicional arquitectura descentralizada de la monarquía ${ }^{41}$. Por el contrario, el protagonismo que Cano confería a la creación de la Gran Compañía y el establecimiento del Puerto Franco apuntaban antes que nada a asegurarse "el gobierno del comercio". De ahí la centralización y el intervencionismo colbertiano que transpiraban sus estatutos, que se sabían sostenidos por el apoyo del monarca; en esa línea, la propuesta tampoco debía de ser ajena a la renovación de la política comercial inaugurada por el ministro francés a raíz de la concesión de puerto franco a Marsella. En cierto sentido Cádiz se insinuaba como la Marsella del Atlántico, en una apuesta en la que la oposición al monopolio corporativo sevillano se intentaba sustituir por un exclusivo comercial abierto a la participación de otras ciudades de la Monarquía, de acuerdo en cualquier caso con lo establecido en los reglamentos de la propia Compañía ${ }^{42}$.

Sustentadas sobre una cierta ingenuidad en relación con la receptividad y viabilidad del cambio propuesto, las expectativas de Cano se verían frustradas. El temor

40 De hecho esa dinámica venía siendo impulsada desde ámbitos territoriales no castellanos, cuyas propuestas fueron oportunamente incorporadas y canalizadas dentro del neoforalismo de don Juan de Austria. Algunos textos del arbitrismo aragonés son muy ilustrativos en ese sentido; ver Fernández Albaladejo, op. cit. (nota 11), pp.461- 464. Sobre la península económica, Pérez Sarrión, op. cit. (nota 14).

41 Conviene tener en cuenta el sentido de la expresión comercio libre dentro del pensamiento mercantilista. Las alusiones a la libertad de comerciar no anticipaban teleológicamente una freedom of trade. El mercantilismo operaba distinguiendo por una parte entre un espacio del bien común (sustentado sobre la tradición escolástica de justicia y centrado en un mercado interior cuya finalidad es el consumo) y, por otra, un espacio exterior vinculado al comercio con los países extranjeros," dominio de la crematística y del arte de adquirir por adquirir". Resumo en este punto a Grenier, J.Y.: "Ordre et désordre. Échange et marchés dans le mercantilisme anglais et français (XVIIe-XVIIIe siècle)", en Isenmann, M. (ed.): Merkantilismus. Wieder Aufnahme einer Debatte, Stuttgart, Franz Steiner Verlag, 2014, pp. 83-11

42 En Francia el plan de renovación conduciría finalmente a la eliminación de los privilegios comerciales de la Compagnie de l'Occcident y al establecimiento en 1717 de un régimen (l'Exclusif) que -combinando privilegio y libertad- permitía el comercio libre a un número limitado de puertos franceses (Cheney, P.: Revolutionary Commerce. Globalization and the French Monarchy, Cambridge, Harvar UP, 2010, pp. 165-173; Horn, J.: "Marseille et la question du mercantilisme", Histoire, Economie \& Société, 2 (2011), pp. 95-111; Carner, G.: “Le mercantilisme: un faux ami?”, en Isenmann, op. cit. (nota 41), pp. 266-288, esp. 278-79. Para Cádiz, Herrero, op. cit. (nota 33), p. 177. 
anticipado por Castro de que el enemigo pudiera estar dentro de casa resultó mucho más realista. De hecho los consejeros ya habían llegado a retenerle en una prisión de la corte, manifestando sin disimulo su oposición al conjunto de sus memoriales y al tono en que venían formulados. La consulta definitiva elevada por el Consejo de Indias (mayo de 1675) a la vista de las proposiciones de Cano no admitía muchas dudas en este sentido: "de ninguna manera es practicable ninguno de los medios que propone Juan Cano". Tan contundente negativa invocaba antes que nada razones de estricta inconstitucionalidad y, aún, de impracticabilidad. Las medidas podrían tener sentido en otros reinos y provincias, pero dado que "las de España se gobiernan con diferentes leyes y ordenanzas" resultaba entonces imposible "executarse todo lo que se propone, assi en lo espiritual como en lo temporal"; de hecho ya los propios presupuestos que se presentaban resultaban "fantásticos y sin ningún fundamento". Y lo que era aún más importante: la aplicación de los Estatutos venía a alterar "todo el orden y gobierno establecido en quanto a la forma del Comercio", cuyas leyes se habían confeccionado de acuerdo con la "calidad naturaleça de cada Provincia". Finalmente y por tratarse de una materia "tan universal" la resolución implicaría a otros Consejos con lo que la posibilidad misma de una resolución desbordaba la capacidad del propio Consejo de Indias ${ }^{43}$.

Todo parece indicar que las cosas no habían ido mucho mejor para Castro. Si bien no tenemos noticia sobre cuál pudo ser la respuesta de consejeros y Consejo -si se produjo-, disponemos al menos de un memorial con "notas opuestas" a los "arbitrios sobre el comercio de Indias" presentados por el agustino. Reconociendo los buenos propósitos de Castro, el autor quería dejar constancia del "engaño" de unas "suposiciones" que "se desunen de lo cierto". Frente a las "suposiciones fantásticas" de aquél, las del objetor se pretendían asentadas sobre "físicos y matemáticos puntos". Consecuente con esa metodología y ateniéndose "al hecho material y palpable", el crítico desplegaba una minuciosa y anotada relación de las fisuras perceptibles en el texto de Castro. Desde las estimaciones de población (tanto en España como en Indias) a los cálculos de consumo interior de los géneros extranjeros o al posible nivel del fraude, nada parecía tenerse en pie en el memorial del agustino. Por el contrario los "reparos" del censor se pretendían dotados de la superioridad que supuestamente le aseguraba su metodología. Certeza a la que no era ajena su conocimiento de primera mano de "la realidad de las Indias" que, insistiendo en su crítica, le permitía poner de manifiesto el cúmulo de errores de cálculo cometidos por Castro en su análisis de las posibilidades de explotación del tráfico comercial de los puertos del golfo del Caribe.

Independientemente de sacar a la luz las supuestas incongruencias del agustino y de censurar su comportamiento en la negociación con la monarquía, el autor de la crítica tampoco perdía la ocasión para postularse como una más fiable alternativa. De hecho ya lo venía intentando desde algunos años atrás: Gabriel Fernández de Villalobos, "marqués de Varinas y Guana Guanaré" que suscribía el informe, no era a estos efectos un desconocido. "Instruydo" en las cosas de Indias y después de 22

43 Lo que como se ve no impidió que, unos meses antes, el libro hubiera visto la luz. Recoge y señala la importancia de ese texto, Díaz Blanco, op. cit. (nota 12), p. 66. Sobre la influencia del entramado corporativo-territorial en ese contexto ver también, Graffe, R.: “The Spanish Reigns and the «Failures» of Mercantilism”, en Stern, P. y Vennerlind, C. (eds.): Mercantilism Reimagined: Political economy in Early Modern Britain ans its Empire, Oxford Scholarship Online, 2014, pp. 1-20. 
años de estancia en ellas, aparece finalmente en la Corte en 1675. Probablemente el escrito en contra de Castro fue redactado en la primera mitad de los ochenta, un momento sobre el que no disponemos de mayores noticias sobre la actividad de este último ${ }^{44}$. A lo largo de esa década Varinas dio forma a una abrumadora producción de escritos sobre Indias, consiguiendo al propio tiempo introducirse en los círculos cortesanos. Omitiendo referir aquí los avatares de una trayectoria que no concluyó demasiado bien, interesa no pasar por alto el motivo -y la novedad- de fondo que movilizaba sus trabajos. En ellos no se trataba tanto de reiterar la importancia de Indias en el nuevo escenario comercial cuanto de transferirles por completo el papel de protagonistas en ese ámbito. Eran los “intereses de Indias" los que debían primar $\mathrm{y}$, con la vista puesta en ellos, debían de plantearse las nuevas medidas que pudieran adoptarse. Ciertamente arbitrismo en Indias ya lo había habido ${ }^{45}$, pero concebido y proyectado en perspectiva y clave peninsular; las Indias venían siendo contempladas como un laboratorio donde aplicar mecánicamente remedios extraídos del ámbito penínsular. Podría decirse que la importancia de Varinas radica en una relativa atlantización de ese arbitrismo original, lo que a su vez implicaba una relectura del espacio americano con la delimitación de las áreas preferentes. Esa reinvención de la jerarquía espacial explica la fijación de Varinas en torno a la zona del Caribe, un maritorio de conexiones marítimas y caminos hacia el interior cuya centralidad aumentaba por momentos ${ }^{46}$. Dentro de un planteamiento cargado de sobreestimación propia e incongruencias de argumentación, Varinas, insistiendo en su conocimiento del terreno, mostraba un escenario privilegiado donde aplicar efectivamente medidas de corte mercantilista impulsadas por la dinastía. Una línea cuyas posibilidades empezarían a concretarse al poco del cambio dinástico de 1700.

Admitiendo que quizás no fuera el primero ni el único en proponerlo en ese momento, Varinas ejemplifica en cualquier caso el momento de transición de un arbitrismo peninsular a un arbitrismo pensado en clave -y desde-el espacio hispanoatlántico. Como el mercantilismo, el arbitrismo - un sublenguaje en última instancia de esa misma matriz- mostraba una notable capacidad de adaptación. De ahí que observando el respeto a las líneas rojas que le imponía su impronta escolástica ${ }^{47}$, intentase al mismo

44 Fernández Albaladejo, op. cit. (nota 13), pp. 471-482. La parte final del resumen que encabeza el "Memorial que presentó fr. Juan de Castro... proponiendo unos arbitrios sobre el comercio de las Indias, y las notas opuestas dellos por el Marqués de Varinas, a quien lo cometió Su Magestad' (BNE, mss. 3034; cursiva nuestra) confirma la confianza de la que parece disfrutar nuestro hombre.

45 Amadori, A.: "Remedios para un cuerpo político que declina: el arbitrismo de Manuel Gaytán de Torres y el estrechamiento de los vínculos trasatlánticos de la monarquía hispánica (siglo XVII)", Anuario de Estudios Americanos, 71/1 (2014), pp. 107-143; Torres, G. Almeida: “¿Un imperio ibérico integrado? El arbitrismo y el imperio ultramarino portugués (1580-1640)", Obradoiro de Historia Moderna, 23 (2013), pp. 71-102. Almarza, S.: "El comercio en el siglo XVIII: arbitrios a las autoridades", Revista de Indias, 175 (1985), pp. 13-25.

46 Sobre la noción de maritorio, como "espacios promisorios de expansión”, aplicada al ámbito caribeño, Fuentes Crispín, M.: Periplos ilustrados, piratas y ladrones en el Caribe colonial, Bogotá, Univ. Nacional de Colombia, 2013. Sobre la centralidad de ese espacio en el debate imperial, Botella, E.: "Debating Empires. The Atlantic imperial ideology and the Spanish- British competition for the Americas. 1660-1720s", The Journal for Early Modern Cultural Studies, 10/1 (2010), pp. 142-168. La perspectiva inglesa en Jarvis, M.: In the Eye of all Trade. Bermuda, Bermudians and the Maritime Atlantic World, 1680-1783, Chapel Hill, Univ. of Carolina Press, 2010. Para el caso francés, Mandelblatt, B.: "How Feeding Slaves Shaped the French Atlantic: Mercantilism and the Crisis of Food Provisioning in the Franco-Caribbean during the Seventeenth and Eighteenth Centuries”, Reinert y Rodge, op. cit. (nota 7), pp. 193-220.

47 Más relevante y constitutiva en ese proceso que lo que habitualmente se le concede, como ya advirtiera en su momento, 1955, Raymond de Roover (J. Kirshner ed.), Business, Banking and Economic Thougth, in Late Medieval and Early Modern Europe, Univ. of Chicago Press, 1974, cap.9, "Scholastic Economics". 
tiempo buscar respuestas inclusivas a las contradicciones planteadas por los nuevos formas de creación de riqueza ${ }^{48}$. Conviene por lo mismo ponderar el alcance de sus propuestas, no convertir a sus proponentes en eslabones perdidos de una cadena que conduciría al advenimiento pleno de la sociedad comercial. Se impone así la contextualización y aún la correcta traducción de un lenguaje que deberá ser tenido muy en cuenta a la hora de encuadrar-de traducir- la modernización de nuestro siglo XVIII.

\section{Bibliografía}

Almarza, S.: "El comercio en el siglo XVIII: arbitrios a las autoridades", Revista de indias, 175 (1985), pp. 13-25.

Alsedo y Herrera, D.: Descripción de los tiempos de España, 1763, (José María Sánchez Molledo ed., Madrid, Polifemo, 2005).

Alloza, A.: "El comercio francés en España y Portugal. La represalia de 1635", en Martínez Shaw, C. y Oliva Melgar, J.M. (eds.): El sistema atlántico español (siglos XVIII-XIX), Madrid, Marcial Pons, 2005, pp. 128-161.

Amadori, A.: "Remedios para un cuerpo político que declina: el arbitrismo de Manuel Gaytán de Torres y el estrechamiento de los vínculos trasatlánticos de la monarquía hispánica (siglo XVII)", Anuario de Estudios Americanos, 71/1 (2014), pp. 107-143.

Aragón Ruano, A.: "Las compañías de comercio armado durante el siglo XVII: los proyectos de 1667 y 1668", Obradoiro de Historia Moderna, 25 (2016) pp. 173-205.

Arnolfini de Illescas, J.: Discurso Hispano Politico sobre el estado presente de la Monarquía, en Hermosa Espejo, C.: Una mirada a la Monarquía española de finales del reinado de Felipe IV, Valladolid, Universidad de Valladolid, 2010.

Baltar Rodríguez, J.: "Proyectos de creación de Compañías privilegiadas en Indias durante el siglo XVII", en Barrios, F. (ed.): Derecho y Administración Pública en las Indias Hispánicas, Cuenca, Universidad de Castilla-La Mancha, 2002, vol.1, pp. 249-264.

Blanc, J. y Desmedt, L.: "In search of a «crude fancy of childhood»: deconstructing mercantilism", Cambridge Journal of Economics, 18 (2013), pp. 1-20.

Botella, E.: "Debating Empires. The Atlantic imperial ideology and the Spanish- British competition for the Americas. 1660-1720s", The Journal for Early Modern Cultural Studies, 10/1 (2010), pp. 142-168.

Cano, J.: Reformación moral, política y christiana del comercio, Madrid, 1675.

Carner, G.: "Le mercantilisme: un faux ami?", en Isenmann, M. (ed.): Merkantilismus. Wieder Aufnahme einer Debatte, Stuttgart, Franz Steiner Verlag, 2014, pp. 266-288.

Clark, H.C.: "Commerce, the Virtues, and the Public Sphere in Early Seventeenth-Century France", French Historical Studies, 21/3 (1998), pp. 415-440.

- Compass of Society. Commerce and Absolutism in Old-Regime France, Lanham, Lexington Books, 2007.

Cheney, P.: Revolutionary Commerce. Globalization and the French Monarchy, Cambridge, Harvar UP, 2010, pp. 165-173.

48 Grenier, op. cit. (nota 41), pp. 83-11 y Magnusson, L.: "Is Mercantilism a Useful Concept", en Isenmann, op. cit. (nota 41), pp. 19-37. Ver también Blanc, J. y Desmedt, L.: "In search of a «crude fancy of childhood»: deconstructing mercantilism", Cambridge Journal of Economics, 18 (2013), pp. 1-20 (debo esta referencia a Pablo Sánchez León); Robinson Rössner, Ph.: "Heckscher Reloaded?. Mercantilism, the State and Europe's Transition to Industrialization, 1600-1900", Historical Journal, 58/2 (2015), pp.624-683. 
De Roover, R. (J. Kirshner ed.), Business, Banking and Economic Thougth, in Late Medieval and Early Modern Europe, Univ. of Chicago Press, 1974.

Delgado Ribas, J.M.: Dinámicas imperiales (1650-1796) España, América y Europa en el cambio institucional del sistema colonial español, Barcelona, Bellaterra, 2007.

Díaz Blanco, J. M.: Así trocaste tu gloria. Guerra y comercio colonial en la España del siglo XVII, Madrid, Marcial Pons, 2012.

— "Pensamiento arbitrista y estructuras institucionales en la carrera de Indias (siglo XVII): entre la desincentivación y la represión", Anuario de Estudios Americanos, 71/1 (2014), pp. $47-77$

Dubet, A.: Hacienda, arbitrismo y negociación política, Valladolid, Universidad de Valladolid, 2003.

Fernández Albaladejo, P.: La crisis de la Monarquía, Madrid, Crítica-Marcial Pons, 2009.

— "Intereses de Indias, dominio del rey: indicios de un debate en la Monarquía de España (1680-1715)", en Andrés, F., Martínez, S., y Hernández, M. (eds.): Mirando desde el puente. Estudios en homenaje al profesor James S. Amelang, Madrid, UAM. 2019, pp. 471-482.

García Fuentes, L.: "La oposición del Consulado de Cargadores a Indias a la creación de compañías comerciales privilegiadas", Temas Americanistas, (17) 2004, pp. 24-37.

Graffe, R.: "The Spanish Reigns and the «Failures» of Mercantilism”, en Stern, P. y Vennerlind, C. (eds.): Mercantilism Reimagined: Political economy in Early Modern Britain ans its Empire, Oxford Scholarship Online, 2014, pp. 1-20.

Grenier, J.Y.: "Ordre et désordre. Échange et marchés dans le mercantilisme anglais et français (XVIIe-XVIIIe siècle)", en Isenmann, M. (ed.): Merkantilismus. Wieder Aufnahme einer Debatte, Stuttgart, Franz Steiner Verlag, 2014, pp. 83-11.

Hartman, J y Westseijn, A: “An Empire of Trade: Commercial Reason of State in Seventeenth Century Holland", en Reinert, S.y Roge, E. (eds.): The Political Economy of Empire in the Early Modern World, Londres, Palgrave, 2013, pp. 11-30.

Herrero Sánchez, M.: “Cádiz y la reorganización del comercio indiano en el proyecto mercantilista de Juan Cano (1675)", Actas del II Congreso de Historia de Andalucía, Córdoba, 1994, vol.6, pp. 171-178.

- (ed.): Repúblicas y republicanismo en la Europa moderna (siglos XVI-XVIII), Madrid, FCE, 2017.

Hont, I.: "Commercial society and political theory in the eighteenth-century: the problem of Authority in David Hume and Adam Smith", en Welching, W. y Welema W. (eds.): Main Trends in Cultural History, Amsterdam, Rodopi, 1994, pp. 55-94.

Horn, J.: "Marseille et la question du mercantilisme", Histoire, Economie \& Societé, 2 (2011), pp. 95-111.

Jarvis, M.: In the Eye of all Trade. Bermuda, Bermudians and the Maritime Atlantic World, 1680-1783, Chapel Hill, Univ. of Carolina Press, 2010.

Jurdjievic, M.: "Virtue, Commerce and the Enduring Florentine Republican Moment", Journal of the Histotry of Ideas, 62/4 (2001), pp. 721-743.

Magnusson, L.: "Is Mercantilism a Useful Concept", en Isenmann, M. (ed.): Merkantilismus. Wieder Aufnahme einer Debatte, Stuttgart, Franz Steiner Verlag, 2014, pp. 19-37.

Mandelblatt, B.: "How Feeding Slaves Shaped the French Atlantic: Mercantilism and the Crisis of Food Provisioning in the Franco-Caribbean during the Seventeenth and Eighteenth Centuries", Reinert, S.y Roge, E. (eds.): The Political Economy of Empire in the Early Modern World, Londres, Palgrave, 2013, pp. 193-220. 
Martínez Shaw, C. y Oliva Melgar, J.M. (eds.): El sistema atlántico español (siglos XVIII-XIX), Madrid, Marcial Pons, 2005.

Matilla, M. J.: "Las compañías privilegiadas en la España del Antiguo Régimen”, en Artola, M. (ed.): La economía española al final del Antiguo Régimen, Madrid, Alianza, 1982, pp. 298-99.

Muñoz Pérez, J.: "El comercio de Indias bajo los Austrias y los tratadistas españoles del siglo XVII", Revista de indias, 68 (1957), pp. 210-221.

Oliva Melgar, J.Ma .: "La metrópoli sin territorio. Crisis del comercio de indias en el siglo XVII o pérdida del control del monopolio", en Martínez Shaw, C. y Oliva Melgar, J.M. (eds.): El sistema atlántico español (siglos XVIII-XIX), Madrid, Marcial Pons, 2005, pp. 19-73.

Pérez Sarrión, G.: La península comercial. Mercado, redes sociales y Estado en España en el siglo XVIII, Madrid, Marcial Pons, 2012, pp. 123-154.

Pincus, S.: "Neither Machiavellian Moment nor Possesive Individualism: Commercial Society and the Defenders of the English Commonwealth", American Historical Review, 103/3 (1998), pp.706-736.

Pocock, J.: Il momento machiavelliano. Il pensiero politico fiorentino e la tradizione republicana anglosassone, Bolonia, Il Mulino, 1980. esp. vol. II, caps. 13-15.

— "Virtues, rights, and manners. A model for historians of political thought", en Virtue, Commerce and History, Cambridge U.P., 1985, pp. 37-50.

— "The Atlantic Republican Tradition: The republic of the Seven Provinces", Republics of Letters: A Journal for the Study of Knowledge, Politics and the Arts, 2, nº1 (2010), pp. $1-10$.

Reinert, S. y Roge, E. (eds.): The Political Economy of Empire in the Early Modern World, Londres, Palgrave, 2013.

Robinson Rössner, Ph.: "Heckscher Reloaded?. Mercantilism, the State and Europe's Transition to Industrialization, 1600-1900”, Historical Journal, 58/2 (2015), pp.624-683.

Ruiz Martín, F.: “La banca en España hasta 1782”, en El Banco de España, una historia económica, Madrid, Banco de España, 1970, pp. 1-196.

Sánchez Molledo, J.Mª .: El pensamiento arbitrista en el Reino de Aragón en los siglos XVI y XVII, Madrid, Univ. Complutense, 1997.

Scornicki, A.: "La France des Lumières et l'humanisme commercial. Bilan et perspectives historiographiques", Histoire, Économie \& Societé, 4 (2013), pp. 76-89.

Torres, G. Almeida: “¿Un imperio ibérico integrado? El arbitrismo y el imperio ultramarino portugués (1580-1640)", Obradoiro de Historia Moderna, 23 (2013), pp. 71-102. 